\title{
Structure and reactivity of Au-Rh bimetallic clusters on titanate nanowires, nanotubes and $\mathrm{TiO}_{2}(110)$
}

\author{
J. Kiss ${ }^{\mathrm{a}, \mathrm{b}}$, L. Óvári ${ }^{\mathrm{b}}$, A. Oszkóa ${ }^{\mathrm{a}}$, G. Pótári ${ }^{\mathrm{a}}$, M. Tóth ${ }^{\mathrm{a}}$, K. Baán ${ }^{\mathrm{a}}$, A. Erdóhelyi ${ }^{\mathrm{a}, \mathrm{b}, *}$ \\ a Department of Physical Chemistry and Material Science, University of Szeged, Aradi vértanúk t. 1, H-6720 Szeged, Hungary \\ ${ }^{\mathrm{b}}$ Reaction Kinetics Research Laboratory, Institute of Nanochemistry and Catalysis, Chemical Research Center of Hungarian Academy of Sciences, \\ P.O.B. 168, Aradi vértanúk t. 1, H-6701 Szeged, Hungary
}

\section{A R T I C L E I N F O}

\section{Article history:}

Received 29 March 2011

Received in revised form 25 May 2011

Accepted 1 June 2011

Available online 30 June 2011

\section{Keywords:}

Core-shell structure

Titania nanowire

Titania nanotube

Gold

Rhodium

Ethanol decomposition

\begin{abstract}
A B S T R A C T
$\mathrm{Au}$ and $\mathrm{Rh}$ clusters, as well as $\mathrm{Au}-\mathrm{Rh}$ bimetallic nanoparticles were prepared on titanate nanowires, nanotubes and on $\mathrm{TiO}_{2}\left(\begin{array}{ll}1 & 1\end{array}\right)$. They were characterized by X-ray photoelectron spectroscopy (XPS), low energy ion scattering spectroscopy (LEIS) and Fourier transform infrared spectroscopy (FTIR). By performing careful LEIS experiments, it was found that for appropriate Au and Rh coverage, a thin Au layer almost completely covers the Rh nanoparticles, a Rh core-Au shell structure was detected. The formation of this structure was not affected by alkali (K) adatoms. LEIS and FTIR measurements disclosed that adsorbed $\mathrm{CO}$ at $300 \mathrm{~K}$ causes the segregation of Rh atoms to the surface of metal clusters in order to bind to $\mathrm{CO}$. Upon $\mathrm{CO}$ adsorption on $\mathrm{Rh} /$ titanate nanostructures the IR stretching frequencies characteristic of the twin form were dominant, whereas bimetallic nanosystems featured a pronounced linear stretching vibration as well. In spite of this structure adsorbed $\mathrm{CO}$ is detectable during the ethanol adsorption on gold-rhodium bimetallic cluster and the ethanol decomposition rate is twice higher than on $\mathrm{Au} / \mathrm{TiO}_{2}$.
\end{abstract}

(c) 2011 Elsevier B.V. All rights reserved.

\section{Introduction}

Highly dispersed gold particles have increasingly gained attention in the catalytic community due to their unusual catalytic properties in a variety of oxidation and hydrogenation reactions [see e.g. Refs. [1-3] and references therein]. Supported bimetallic catalysts have been shown to exhibit superior catalytic performances when compared to their monometallic counterparts [4,5]. Depending on the nature of the second metal, different kinds of mechanisms were observed in the interactions with bimetals. Both ligand effects (i.e. an electronic factor due to the change in electron density) and ensemble effects (i.e. surface structure factor due to the positioning of different atom types) can contribute to synergetic effects often observed for bimetallic surface particles [6-8]. Enhanced dispersion and stability of gold nanoparticles on stoichiometric and reduced $\mathrm{TiO}_{2}(110)$ were observed in the presence of molybdenum [9]. It has also been observed that Rh significantly changed the morphology and topology of Au on $\mathrm{TiO}_{2}(110)$ surface $[10,11]$. STM and low energy ion scattering spectroscopy (LEIS) experiments revealed that at proper Au and Rh coverage the postdeposited Au completely and uniformly covers the Rh nanoparticles

\footnotetext{
* Corresponding author at: Department of Physical Chemistry and Material Science, University of Szeged, Aradi vértanúk t. 1, H-6720 Szeged, Hungary. Tel.: +36 62 343638; fax: +36 62546482 .

E-mail address: erdohely@chem.u-szeged.hu (A. Erdóhelyi).
}

(core-shell structure). In the case of the Au-Pd system the results show segregation of gold to the surface. Density functional theory calculation confirms that Au prefers to be at the edges of AuPd alloy particles under vacuum conditions [12]. The presence of Pt in the bimetallic Pt-Au clusters inhibits sintering, and the average size of the clusters after annealing decreases with increasing Pt content. Based on LEIS and STM experiments, performed on $\mathrm{TiO}_{2}(110)$, it was stated that the deposition of Au on Pt clusters results in the formation of bimetallic clusters due to the seeding of mobile $\mathrm{Au}$ atoms at existing Pt nuclei, but the deposition of $\mathrm{Au}$ on Pt does not produce core-shell structures with Au on top at small coverages [13]. Later on the formation of Pt core-Au shell structures was demonstrated at higher coverages (0.25-0.5 ML). Adsorption of $\mathrm{CO}$ on the Pt clusters covered by the gold capping layer promoted the diffusion of Pt atoms to the cluster surface in order to bind to $\mathrm{CO}$ [14].

In addition to the above findings it turned out that the nature of the support (i.e. $\mathrm{Fe}_{2} \mathrm{O}_{3}(111), \mathrm{MgO}(100)$, and $\mathrm{CeO}_{2}(111)$ ) often plays a critical role in reactivity $[4,5,12]$. The observed vibrational frequency of $\mathrm{CO}$ adsorbed on the surface can be used to identify its specific binding sites and thus to elucidate the surface composition. Desorption of CO as a function of temperature provides similar information and supports the identification of binding sites on the surface. This approach has been successfully applied in the past to investigate $\mathrm{Au}-\mathrm{Pd}$ alloy surfaces [15], Au-Pd particles supported on $\mathrm{SiO}_{2}$ [16] and $\mathrm{Al}_{2} \mathrm{O}_{3}$ film [17], $\mathrm{Au}-\mathrm{Rh}$ bilayers on supported powder $\mathrm{TiO}_{2}[18]$ and on titanate nanowire and nanotubes $[19,20]$. 
Low energy ion scattering spectroscopy (LEIS), besides other surface sensitive techniques, was successfully applied in the characterization of bimetallic nanoclusters on $\mathrm{TiO}_{2}(110)$ [9-11,13,14], because it has very high sensitivity in the topmost layer. In this paper we use this technique with XPS and FTIR methods to investigate the effect of potassium in the arrangement of Au-Rh clusters on $\mathrm{TiO}_{2}\left(\begin{array}{lll}1 & 1 & 0\end{array}\right)$ surface and on titanate nanowire and nanotubes supports.

One-dimensional nanostructures have been in the focus of the material science community for well more than a decade now [21]. Although carbon nanotubes may solve many challenges of materials engineering in the long run, at present their practical applicability appears to be limited by the lack of adequately selective synthesis technologies. On the other hand, inorganic nanostructures (e.g. metallic nanowires, oxides, sulfides, selenides, etc.) can be prepared in a rather controlled manner, and therefore their industrial-scale application is very close now.

Titanate nanotubes are also of great interest for catalytic applications, since their high cation exchange capacity provides the possibility of achieving a high metal dispersion [22]. In this regard, there are several demonstrated examples of successful utilization of titanate nanotubes as mesoporous catalyst supports for different nanoparticles. High-aspect-ratio $\mathrm{TiO}_{2}$ and titanate nanoobjects are intensively studied at present because of their promising photoelectrical [23,24], biomedical [25], and hydrogen storage properties [26-28]. Gold-containing titania nanotubes were found to display higher activity in the photo-oxidation of acetaldehyde [29], the water-gas shift reaction [30], and CO oxidation [31] than the Degussa P-25 catalyst.

In this paper, we shall use the term "nanotube" for highaspect-ratio objects with a hollow inner channel below $50 \mathrm{~nm}$ and "nanowire" for high-aspect-ratio objects without an inner void and a diameter below $200 \mathrm{~nm}$.

The catalytic activity of titanate structures was tested in the ethanol decomposition. Catalytic conversion of bio-ethanol received considerable attention in the last decade [32-37] and the search for the most active, stable and selective catalyst has resulted in many heterogeneous catalytic systems.

Supported $\mathrm{Rh}$ is one of the best samples for these reactions, but only a few papers deal with the efficiency of supported Au. Idriss et al. [38] studied the oxidation of ethanol on $\mathrm{Au} / \mathrm{CeO}_{2}$, and the adsorption and desorption of it on $\mathrm{Au} / \mathrm{TiO}_{2}$ [39]. Guan and Hensen [40] recently examined the dehydrogenation of ethanol on Au nanoparticles deposited on various $\mathrm{SiO}_{2}$ supports. A strong influence of the Au particle size was observed. It is noteworthy that, in the presence of oxygen, the intrinsic activity of $\mathrm{Au} / \mathrm{SiO}_{2}$ increased considerably. Lippits and Nieuwenhuys [41] investigated the conversion of ethanol into ethylene oxide on gold-based catalysts. It was found that when gold was added to the $\mathrm{Al}_{2} \mathrm{O}_{3}$ support the catalyst produced ethylene oxide which was not observed on the support alone. The presence of gold nanoparticles is necessary for the formation of ethylene oxide. Solymosi and co-workers [37] studied the ethanol decomposition on Au nanoparticles deposited on various oxides. The formation of hydrogen and the product distribution depended sensitively on the nature of the support. These samples catalyze mainly the dehydrogenation of ethanol, to produce hydrogen and acetaldehyde. The highest rate of hydrogen evolution was observed on $\mathrm{Au} / \mathrm{CeO}_{2}$.

\section{Experimental}

Titanate nanowires and nanotubes were prepared by hydrothermal conversion of anatase $\mathrm{TiO}_{2}$ as described elsewhere [42,43]. Briefly, the nanostructures were prepared by mixing $2 \mathrm{~g}$ of anatase into $140 \mathrm{~cm}^{3} 10 \mathrm{M}$ aqueous $\mathrm{NaOH}$ solution until a white suspension was obtained, aging the suspension in a closed, cylindrical,
Teflon-lined autoclave at $400 \mathrm{~K}$ for $1-72 \mathrm{~h}$ while rotating the whole autoclave intensively at $60 \mathrm{rpm}$ around its short axis, and finally washing the product with deionized water and neutralizing with $0.1 \mathrm{M} \mathrm{HCl}$ acid solution to reach $\mathrm{pH}=7$; at this point, the slurry was filtered and the residue was dried in air at $353 \mathrm{~K}$. $\mathrm{Au}, \mathrm{Rh}$ and their coadsorbed layers with different compositions were produced by impregnating titania nanowires and nanotubes with the mixtures of calculated volumes of $\mathrm{HAuCl}_{4}$ (Fluka) and $\mathrm{RhCl}_{3} \cdot 3 \mathrm{H}_{2} \mathrm{O}$ (Johnson Matthey) solutions to yield $1 \mathrm{wt} \%$ metal content. In the bimetallic catalyst the $\mathrm{Au} / \mathrm{Rh}$ atomic ratio was 1 . The impregnated powders were dried in air at $383 \mathrm{~K}$ for $3 \mathrm{~h}$, than oxidized at $573 \mathrm{~K}$. The final pre-treatment was at $573 \mathrm{~K}$ in hydrogen atmosphere [18].

Titanate nanotubes are open ended hollow tubular objects measuring $7-10 \mathrm{~nm}$ in outer diameter and $50-170 \mathrm{~nm}$ in length. They feature a characteristic spiral cross section composed of 4-6 wall layers. The typical diameter of their inner channel is $5 \mathrm{~nm}$. Titanate nanowire represents the thermodynamically most stable form of sodium trititanate under the applied alkaline hydrothermal conditions (note that the post-synthetic neutralization step converts the original $\mathrm{Na}_{2} \mathrm{Ti}_{3} \mathrm{O}_{7}$ into its hydrogen form without affecting the nanowire morphology). Their diameter is $45-110 \mathrm{~nm}$ and their length is between 1.8 and $5 \mu \mathrm{m}$. The specific surface area of titanate nanotubes is rather large $\left(\sim 185 \mathrm{~m}^{2} \mathrm{~g}^{-1}\right)$ due to their readily accessible inner channel surface, whereas that of solid titanate nanowires is $\sim 20 \mathrm{~m}^{2} \mathrm{~g}^{-1}$. The impurity level of produced nanocomposites was less than $1 \%$. The foreign elements determined by XPS were $\mathrm{K}, \mathrm{Ca}$, $\mathrm{Mg}$ and $\mathrm{Na}$ remained from the preparation process.

The ultra high vacuum experiments were done in two separate chambers. One of them (1) was used to analyze the high area titanate samples, while measurements related to $\mathrm{TiO}_{2}\left(\begin{array}{ll}1 & 10\end{array}\right)$ were conducted in the other (2).

1.XP spectra were taken with a SPECS instrument equipped with a PHOIBOS 150 MCD 9 hemispherical analyzer. The analyzer was operated in the FAT mode with $20 \mathrm{eV}$ pass energy. The $\mathrm{Al} \mathrm{K}_{\alpha}$ radiation $(h v=1486.6 \mathrm{eV})$ of a dual anode X-ray gun was used as an excitation source. The gun was operated at the power of $150 \mathrm{~W}$ $(12.5 \mathrm{kV}, 12 \mathrm{~mA})$. The energy step was $25 \mathrm{meV}$, electrons were collected for $100 \mathrm{~ms}$ in one channel. Typically five scans were summed to get a single high resolution spectrum. For binding energy reference the $\mathrm{Ti} 2 \mathrm{p}_{3 / 2}$ maximum $(458.9 \mathrm{eV})$ was used. The same data were obtained when $\mathrm{C} 1 \mathrm{~s}$ (adventitious carbon at $285.1 \mathrm{eV}$ ), or O $1 \mathrm{~s}$ lattice oxygen ( $530.4 \mathrm{eV}$ ) was used as references. A sample preparation chamber was directly connected to the measuring chamber to avoid the contamination of samples between each step. For spectrum acquisition and evaluation both manufacturer's (SpecsLab2) and commercial (CasaXPS, Origin) software packages were used.

A SPECS IQE 12/38 ion source was used for generation of lowenergy scattering (LEIS) spectra. $\mathrm{He}^{+}$ions of $800 \mathrm{eV}$ kinetic energy were applied at a low ion flux equal to $0.03 \mu \mathrm{A} / \mathrm{cm}^{2}$, which was necessary to avoid the sputtering of surface. The incident angles was $55^{\circ}$ (with respect to surface normal), ions ejected along the surface normal were detected. The ion energies (LEIS) were measured by the same hemispherical energy analyzer as mentioned above.

2. Experiments related to the $\mathrm{TiO}_{2}(110)$ single crystal were conducted in a separate UHV chamber. The crystal was a product of PI-KEM. Its temperature could be changed between 150 and $1000 \mathrm{~K}$. The sample was cleaned at $1000 \mathrm{~K}$, applying $\mathrm{Ar}^{+}$ion sputtering $(2.5 \mu \mathrm{A}, 1.5 \mathrm{keV}, 10 \mathrm{~min})$ and vacuum annealing ( $5 \mathrm{~min})$ cycles. The final treatment was $\mathrm{Ar}^{+}$ion sputtering at $300 \mathrm{~K}$ (30 min). Metals were deposited from an e-beam evaporator of Oxford Applied Research. The chamber had facilities for Auger electron spectroscopy (AES), XPS and LEIS. Electrons as well as $\mathrm{He}^{+}$ions were detected by a Leybold EA 10/100 hemispherical analyzer. During LEIS measurements, the incident and detection angles were $50^{\circ}$ (with respect to surface normal), and the scattering angle was $95^{\circ}$. 
An $\mathrm{Al} \mathrm{K}_{\alpha}$ anode was used as an X-ray source, and the binding energy scale was referenced to the $4 f_{7 / 2}$ peak of a thick Au layer set to $83.8 \mathrm{eV}$.

IR studies were performed in a high vacuum system. The samples were pressed onto a Ta-mesh. The mesh was fixed to the bottom of a conventional UHV sample manipulator. It was resistively heated and the temperature of the sample was measured with a $\mathrm{NiCr}-\mathrm{Ni}$ thermocouple spot welded directly to the mesh. IR spectra were recorded with a Genesis (Mattson) FTIR spectrometer. The whole optical path was purged by a Balston 75-62 FTIR purge generator.

DRIFT spectra were registered during the ethanol adsorption with Bio-Rad FTIR spectrometer with wave number accuracy of $\pm 4 \mathrm{~cm}^{-1}$. The instrument was equipped with a diffuse reflectance attachment (Spectra-Tech) with $\mathrm{BaF}_{2}$ windows. Typically 32 scans were registered. The catalysts were pretreated as mentioned above and the sample was cooled down to room temperature. Then ethanol was introduced into the cell by bubbling Ar gas through ethanol at $273 \mathrm{~K}$ while the sample was heated linearly with a heating rate of $10 \mathrm{~K} / \mathrm{min}$ up to $573 \mathrm{~K}$. The IR spectra were registered continuously.

The catalytic experiments were carried out in a fixed bed continuous flow reactor ( $8 \mathrm{~mm}$ o.d. quartz tube), which was heated externally. The dead volume of the reactor was filled with quartz beads. For catalytic studies small fragments $(1-3 \mathrm{~mm})$ of slightly compressed pellets were used. Typically $50 \mathrm{mg}$ of catalysts was used. Ethanol was introduced into the reactor by bubbling the carrier gas $(\mathrm{Ar} 80 \mathrm{ml} / \mathrm{min}$ ) through liquid ethanol cooled to $273 \mathrm{~K}$. Analysis of the products and reactants was performed with a Chrompack 9001 gas chromatograph using Porapack QS column. The gases were detected simultaneously by TC and FI detectors.

\section{Results and discussion}

\subsection{LEIS experiments obtained on a potassium containing $\mathrm{TiO}_{2}\left(\begin{array}{lll}1 & 1 & 0\end{array}\right)$ surface}

In our previous papers it was demonstrated that Rh core-Au shell clusters can be prepared on $\mathrm{TiO}_{2}(110)$ if $\mathrm{Au}$ is postdeposited by physical vapor deposition (PVD) on the oxide surface containing Rh clusters $[10,11]$. No separate Au clusters formed in the process at a substrate temperature of $500 \mathrm{~K}$. The existing Rh clusters act as nucleation centers for gold atoms deposited subsequently. The high diffusion rate of Au atoms on the oxide during evaporation probably plays an important role in this process. Earlier [11] we demonstrated that the formation of core-shell Rh-Au particles did not depend on the state of reduction of the surface: it proceeded both on unreconstructed $\mathrm{TiO}_{2}(110)$ and also on the more reduced $\mathrm{TiO}_{2}\left(\begin{array}{lll}1 & 1 & 0\end{array}\right)-\left(\begin{array}{l}1 \\ 1\end{array} 2\right)$.

The thermodynamic driving force that $\mathrm{Au}$ atoms tend to be outside within bimetallic clusters comes from the significantly lower surface free energy of Au compared to Rh [44]. When the reverse deposition sequence was applied, i.e. Rh was deposited on the $\mathrm{Au} / \mathrm{TiO}_{2}\left(\begin{array}{lll}1 & 1 & 0\end{array}\right)$ surface, a very efficient place exchange between $\mathrm{Rh}$ and Au atoms was observed by LEIS even at room temperature, moving Rh atoms into subsurface regions of bimetallic clusters and the cluster surface remained covered by gold [10]. This indicates that diffusion processes within small metal clusters are rather facile compared to bulk materials.

Considering the important role of alkali promoters in catalysis and that alkaline atoms/ions are typical constituents/impurities in titanate nanotubes and nanowires it seemed worth investigating whether the formation of core-shell $\mathrm{Rh}$-Au clusters proceeds on a potassium containing $\mathrm{TiO}_{2}\left(\begin{array}{lll}1 & 1 & 0\end{array}\right)$ surface as well.

The potassium overlayer was prepared by thermal segregation: annealing the cleaned sputtered surface at $T \geq 800 \mathrm{~K}$ ( $5 \mathrm{~min}$ )

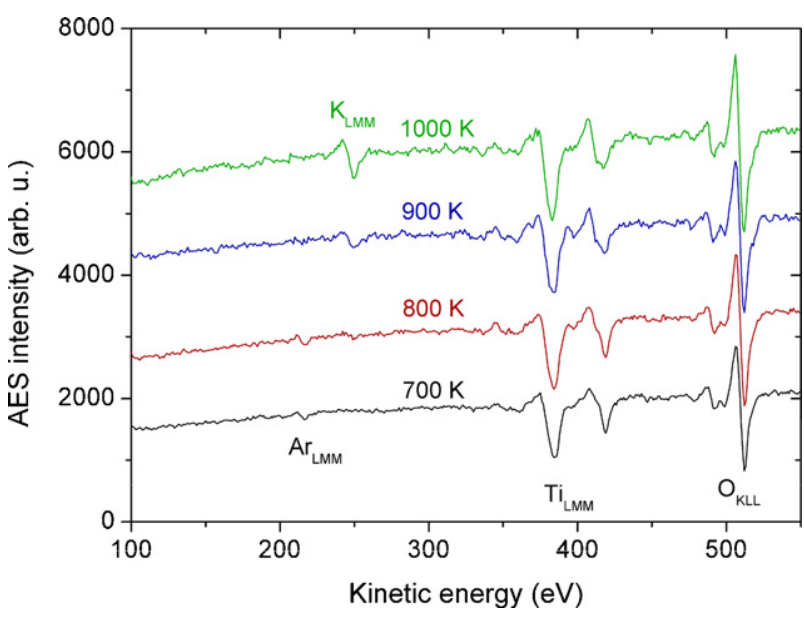

Fig. 1. Auger spectra obtained after annealing the $\mathrm{TiO}_{2}(110)$ surface - previously $\mathrm{Ar}^{+}$sputtered at $300 \mathrm{~K}-$ at higher temperatures in UHV for $5 \mathrm{~min}$.

resulted in the appearance of potassium on the surface detected by AES and XPS. Generally, the potassium content of a $\mathrm{TiO}_{2}$ crystal is exhausted by sputtering-annealing cycles within a few weeks, but with this sample the K coverage obtained by the 5 min annealing at $1000 \mathrm{~K}$ was stable during the period of these experiments ( $\sim 2$ month), characterized by a K/Ti AES ratio of 0.4 monitoring the $\mathrm{K}_{\mathrm{LMM}}(252 \mathrm{eV})$ and $\mathrm{Ti}_{\mathrm{LMM}}(387 \mathrm{eV})$ peaks (Fig. 1). Other typical impurities ( $\mathrm{Ca}, \mathrm{Na}$ ) were not present on this surface.

The chemical state of the potassium containing $\mathrm{TiO}_{2}(110)$ surface obtained after $5 \mathrm{~min}$ annealing at $1000 \mathrm{~K}$ was analyzed by XPS. The Ti $2 \mathrm{p}_{3 / 2}$ peak was observed at $458.7 \mathrm{eV}$ (not shown), which is typical for $\mathrm{Ti}^{4+}$ ions in the titania surface. Apparently no dramatic shifts or increased reduction was found due to the presence of potassium. The Ti $2 \mathrm{p}$ feature, collected at a detection angle of $16^{\circ}$ (with respect to surface normal) contained a small contribution of $\mathrm{Ti}^{3+}$ sites, with an area of ca. $6.5 \%$ compared to the area of the $\mathrm{Ti}^{4+}$ doublet. This is rather typical for a used $\mathrm{TiO}_{2}\left(\begin{array}{lll}1 & 1 & 0\end{array}\right)$ crystal, already colored dark blue. The peak positions were identical, when the Ti $2 \mathrm{p}$ region was monitored at a grazing $\left(71^{\circ}\right)$ detection angle, resulting in a smaller information depth. However, the extent of reduction was somewhat larger, resulting in $\mathrm{ai}^{3+}$ component with an area of ca $10 \%$ of the area corresponding to the $\mathrm{Ti}^{4+}$ component. Evidently this difference is a clear sign that more defect sites exist in the top surface region. The $\mathrm{K} 2 \mathrm{p}_{3 / 2}$ peak (not shown) was found at $294.0 \mathrm{eV}$ indicating that $\mathrm{K}$ atoms at the surface are partially ionized [45].

The possible formation of core-shell Rh-Au clusters on the

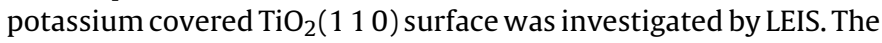
scattering angle in that chamber was relatively small $\left(95^{\circ}\right)$, which is advantageous for the sensitivity, but results in a lower resolution. Consequently, the LEIS contributions of $\mathrm{K}$ and Ti are merged into one peak, because of the similar masses of these elements. First, $0.5 \mathrm{ML}$ of $\mathrm{Rh}$ was evaporated on $\mathrm{K} / \mathrm{TiO}_{2}(110)$ at a substrate temperature of $330 \mathrm{~K}$. Annealing to $500 \mathrm{~K}$ did not cause any appreciable change monitored by LEIS. Gold was subsequently deposited at $500 \mathrm{~K}$ and the changes in the LEIS intensities as a function of $\mathrm{Au}$ coverage are shown in Fig. 2.

The Rh peak decreased steeply with increasing amounts of gold, while the intensities of the $O$ peak and of the peak corresponding to $\mathrm{K}$ and Ti were only mildly attenuated. Evidently Au atoms evaporated on the sample nucleated on existing Rh clusters. If only $\mathrm{Au}$ atoms landed on top of Rh clusters during evaporation had been stabilized on top of Rh, than the complete disappearance of Rh signal would have occurred approximately at the coverage of $1 \mathrm{ML}$ or even above, considering the curvature of the clusters. However, the Rh signal in our measurements decreased to zero at a much 


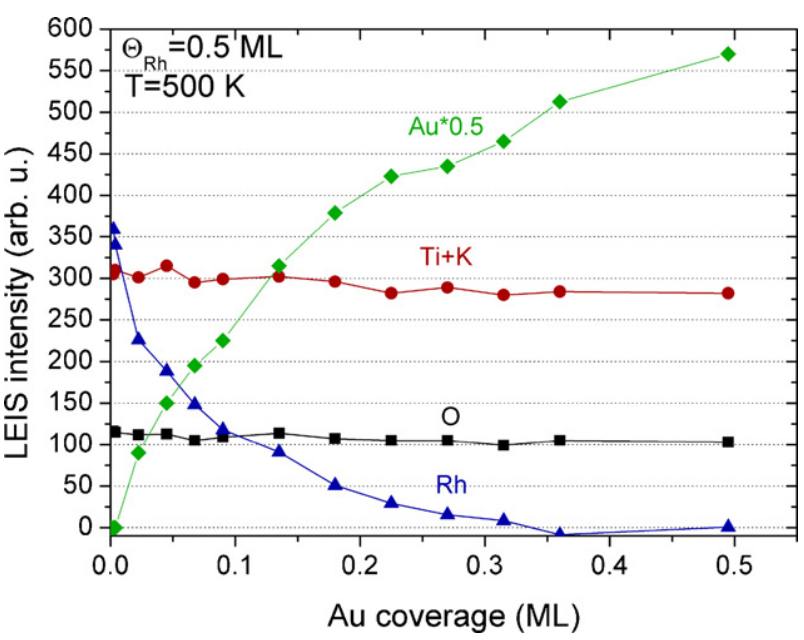

Fig. 2. Changes in LEIS intensities due to Au deposition at $500 \mathrm{~K}$ on the $\mathrm{K} / \mathrm{TiO}_{2}\left(\begin{array}{ll}1 & 1\end{array}\right)$ surface precovered with $0.5 \mathrm{ML}$ of Rh.

smaller coverage $(0.35 \mathrm{ML})$. This indicates that a major fraction of gold atoms - impinged on the free oxide surface during evaporation - migrated to Rh clusters and was stabilized there, similarly as it was demonstrated for the potassium-free $\mathrm{TiO}_{2}(110)$ surface in our previous papers [10,11]. At a substrate temperature of $450 \mathrm{~K}$ analogue results were obtained, but the process was not investigated at even lower $T$ values in order to avoid the effect of background $\mathrm{CO}$ on LEIS intensities.

\subsection{Results obtained on titanate nanowires and nanotubes}

The surface composition of Au-Rh clusters on titanate nanocomposite was also investigated by LEIS. As was observed in the case of $\mathrm{TiO}_{2}(110)$ substrate, with increasing gold content the Rh LEIS intensity decreased dramatically. The most pregnant feature was observed in the $0.5 \% \mathrm{Au}+0.5 \% \mathrm{Rh}$ case. On the monometallic systems the gold and rhodium $\mathrm{He}^{+}$scattering signals appeared at 753 and $707 \mathrm{eV}$, respectively. On bimetallic nanocomposite, however, only the gold signal showed up (Fig. 3) [20]. The rhodium peak was just a bit higher than the noise level. It is very interesting that while the gold content is less (0.5\%) in bimetallic system, the LEIS intensity of $\mathrm{Au}$ is higher than in the monometallic (1\%) case.

On the monometallic $\mathrm{Rh} / \mathrm{TiO}_{2}$ nanowire the dominant XP peak for $\mathrm{Rh} 3 \mathrm{~d}_{5 / 2}$ appeared at $307.1 \mathrm{eV}$ after reduction at $573 \mathrm{~K}$ (not shown). The tailing at the higher binding energy side of this emission may consist of the original asymmetry and trace of foreign element (Mg KLL Auger peak) that remained from the preparation process. A careful deconvolution revealed some emission at $309.3 \mathrm{eV}$, presumably due to more dispersed nanoparticles. Very similar rhodium XP spectra were recorded on titanate nanotubes. In the case of the $1 \% \mathrm{Au} / \mathrm{TiO}_{2}$ nanowire two peaks were observed on the reduced sample for $\mathrm{Au} 4 \mathrm{f}_{7 / 2}$ at $83.7 \mathrm{eV}$ (metallic state) and $85.6 \mathrm{eV}$. The emission at $85.6 \mathrm{eV}$ cannot be attributed to a kind of higher oxidation state, because it developed after hydrogen treatment at $573 \mathrm{~K}$. We may attribute this feature to gold atoms in very small sized nanoparticles ("final-state" effect) [19,20]. Under drastic conditions of an oxygen plasma gold oxide formation was observed; the $\mathrm{Au} 4 \mathrm{f}_{7 / 2}$ was observed above $85 \mathrm{eV}$ [46]. We found that the feature at $85.6 \mathrm{eV}$ appeared only after reduction and not after oxidation so we exclude the oxidized Au formation.

The XP spectra of the bimetallic Au + Rh layer supported on titania nanowires are shown in Fig. 4. Surprisingly, the emission for the higher energy peak of $\mathrm{Au} 4 \mathrm{f}_{7 / 2}$ at $85.6 \mathrm{eV}$ corresponding to the atomically dispersed state is very small in the presence of Rh (Fig. 4A), and at the same time the emission for $\mathrm{Rh} 3 \mathrm{~d}_{5 / 2}$ at around $309.3 \mathrm{eV}$

\section{LEIS spectra taken on titanate nanowire}
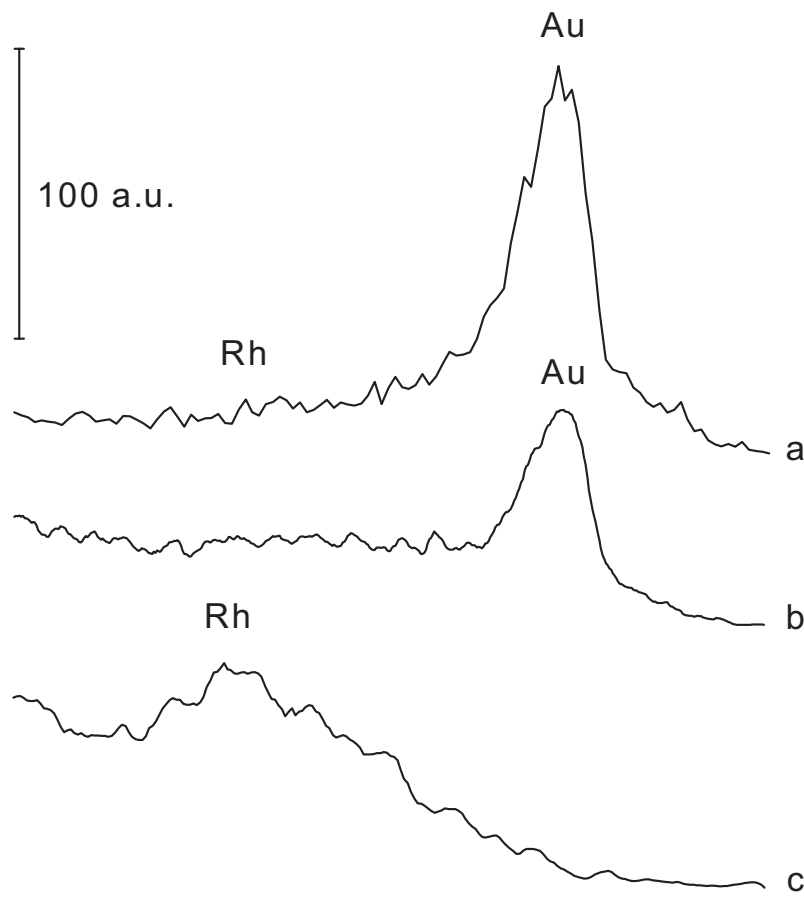

\begin{tabular}{|c|c|c|c|c|c|}
\hline$T$ & $T$ & $T$ & $T$ & $T$ & \\
\hline 680 & 700 & 720 & 740 & 760 & 780 \\
\hline \multicolumn{6}{|c|}{ Kinetic energy [eV] } \\
\hline
\end{tabular}

Fig. 3. LEIS spectra of $1 \% \mathrm{Au} / \mathrm{TiO}_{2}$ (b), $1 \% \mathrm{Rh} / \mathrm{TiO}_{2}$ nanowire (c), $0.5 \% \mathrm{Au}+0.5 \%$ $\mathrm{Rh} / \mathrm{TiO}_{2}$ nanowire (a) [20].

also diminished. The adsorption of $\mathrm{CO}$ at $300 \mathrm{~K}$ did not alter the position of gold emissions. The Rh XPS feature at 308.9-309.3 eV appeared or intensified a little bit after 60 min CO adsorption may be due to the appearance of more dispersed particles (Fig. 4B). The $\mathrm{CO}$ pressure was $1.3 \mathrm{mbar}$ in the preparation chamber.

The morphology of $\mathrm{Au}, \mathrm{Rh}$ and $\mathrm{Au}+\mathrm{Rh}$ supported on $\mathrm{TiO}_{2}$ nanowires and nanotubes was investigated by FTIR, employing adsorbed $\mathrm{CO}$ as a probe molecule sensitive to the local surface structure. Adsorbed CO exhibits at least three different stretching frequencies belonging to certain adsorption sites of $\mathrm{Rh}$ on oxide supports [46]. The band at $2070-2030 \mathrm{~cm}^{-1}$ is due to CO adsorbed linearly to $\mathrm{Rh}^{0}$ (depending on the coverage), the band at $\sim 1855 \mathrm{~cm}^{-1}$ represents the bridge bonded $\mathrm{CO}\left(\mathrm{Rh}_{2}-\mathrm{CO}\right)$, and the feature at $\sim 2100 \mathrm{~cm}^{-1}$ and at $\sim 2020 \mathrm{~cm}^{-1}$ corresponds to the symmetric and asymmetric stretchings of $\mathrm{Rh}^{+}(\mathrm{CO})_{2}$ (twin $\mathrm{CO}$ ). These latter IR signals were detected when the crystallite size was very small [47]. CO adsorption on gold supported on titania nanostructure was not observed. On monometallic Rh supported on nanowire practically the twin form was present $\left(2027\right.$ and $\left.2097 \mathrm{~cm}^{-1}\right)$, the linear form between these two peaks was much smaller and the bridge form was hardly observable (Fig. 5A). On nanotubes the linearly adsorbed $\mathrm{CO}$ features showed up at $2075 \mathrm{~cm}^{-1}$ between the peaks at 2100 and $2036 \mathrm{~cm}^{-1}$ (twin form) (not shown). From these IR studies we may conclude that a significant part of Rh exists in small particle sizes on both nanowires and tubes.

It is plausible if the gold completely and uniformly covers the Rh nanoparticles (core-shell structure) adsorbed CO could not be detected by FTIR. However, the situation is that relatively strong $\mathrm{CO}$ bands appeared at $300 \mathrm{~K}$ at a pressure of $1.3 \mathrm{mbar}$. In the presence 
A
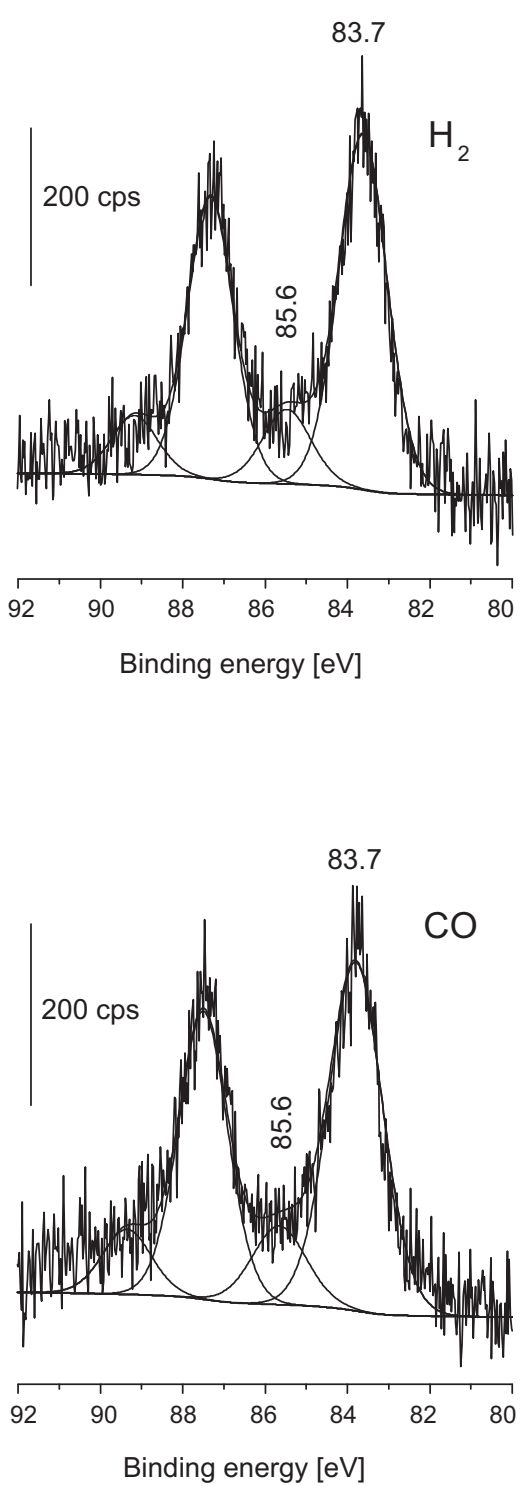

B
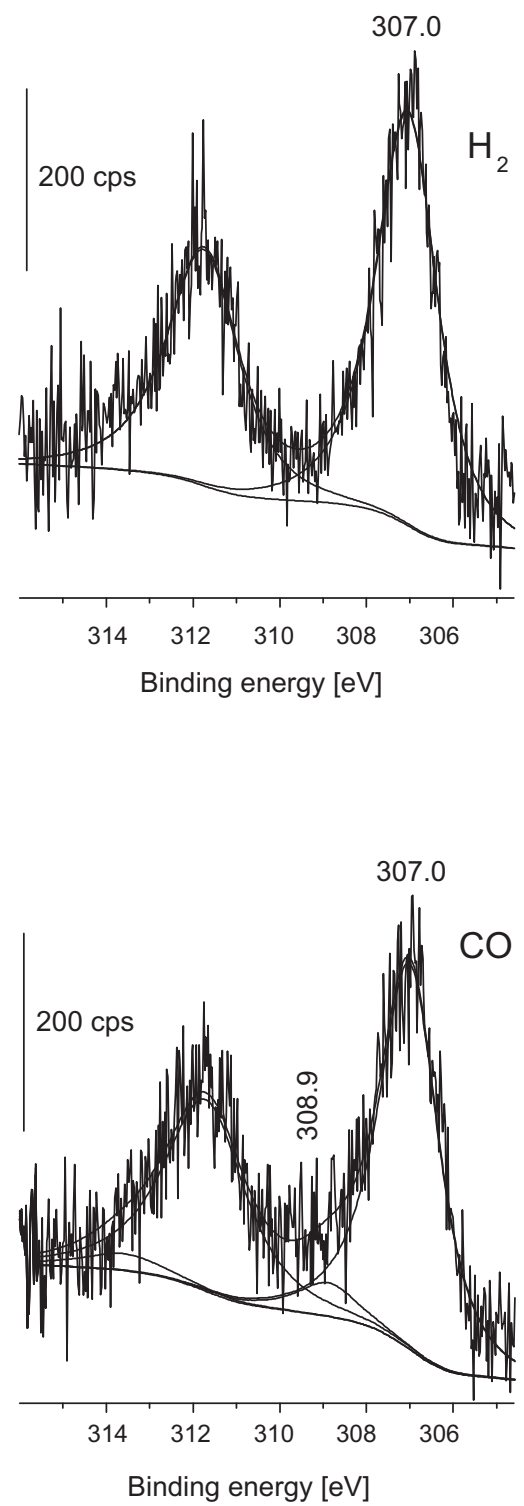

Fig. 4. XP spectra of $\mathrm{Au} 4 \mathrm{f}(\mathrm{A})$ and $\mathrm{Rh} 3 \mathrm{~d}(\mathrm{~B})$ of $0.5 \% \mathrm{Au}+0.5 \% \mathrm{Rh} / \mathrm{TiO}_{2}$ nanowire before and after $\mathrm{CO}$ treatment. The CO pressure was $1.3 \mathrm{mbar}$.

of gold, the peak corresponding to the linear form became stronger at $2070-2071 \mathrm{~cm}^{-1}$ and the twin $\mathrm{CO}$ stretching frequencies decreased (Fig. 5B). Seemingly there is a contradiction between the results of LEIS and CO adsorption infrared experiments. On the topmost layer there are no Rh atoms (Fig. 3), but adsorbed CO was detected by FTIR on this surface (Fig. 5B). This discrepancy can be explained by a $\mathrm{CO}$ induced surface reconstruction. The adsorption of $\mathrm{CO}$ on $\mathrm{Au}-\mathrm{Rh}$ clusters may promote the diffusion of Rh to the surface of the cluster. Similar phenomena was observed recently in the case of bimetallic Pt-Au clusters on $\mathrm{TiO}_{2}(110)$ [14]. The same effect was also observed on $\mathrm{Pd}-\mathrm{Au}$ bimetallic model catalysts, synthesized either as thin films on Mo(1 10$)$ or as nanoparticles on $\mathrm{TiO}_{2}$ thin film in $\mathrm{CO}$ oxidation at elevated (8-16 Torr) CO pressures [48]. Pd preferentially segregates to the surface to form contiguous $\mathrm{Pd}$ sites and $\mathrm{CO}$ oxidation reactivity is regained. The differences obtained on FTIR spectra between monometallic Rh and bimetallic $\mathrm{Au}-\mathrm{Rh}$ nanoclusters on titanate nanowire are not surprising. The presence of the core-shell composites and the separate highly dispersed gold clusters may significantly affect the morphology and electronic structure of Rh nanoparticles therefore the bonding modes of $\mathrm{CO}$ adsorbed on Rh sites. The observed FTIR feature may be related to the XPS result detected after CO adsorption. The morphology and crystallite size of segregated Rh could be different in surrounding of Au-Rh core-shell and in the inside of the core-shell structure.

In order to get closer to the understanding of CO-induced morphological changes some low energy ion scattering measurements (LEIS) were carried out before and after CO adsorption on Au-Rh bimetallic cluster supported on titanate nanotubes. In these experiments two compositions were used: $0.25 \% \mathrm{Au}+0.75 \% \mathrm{Rh} / \mathrm{TiO}_{2}$ and $0.5 \% \mathrm{Au}+0.5 \% \mathrm{Rh} \% / \mathrm{TiO}_{2}$ nanotubes. The results are represented in Fig. 6. In order to avoid or minimize the sputtering effect of the He ions we applied relatively low ion flux $\left(0.03 \mu \mathrm{A} / \mathrm{cm}^{2}\right)$. At the lower gold content rhodium scattering appeared at $707 \mathrm{eV}$ after hydrogen treatment at $573 \mathrm{~K}$. After CO adsorption at $300 \mathrm{~K}$ its intensity increased by about 20\% (Fig. 6A). The effect of adsorbed CO was more pronounced in the $0.5 \% \mathrm{Au}+0.5 \% \mathrm{Rh}$ case. Practically no or very small $\mathrm{Rh}$ scattering signal was detected indicating that the 
A

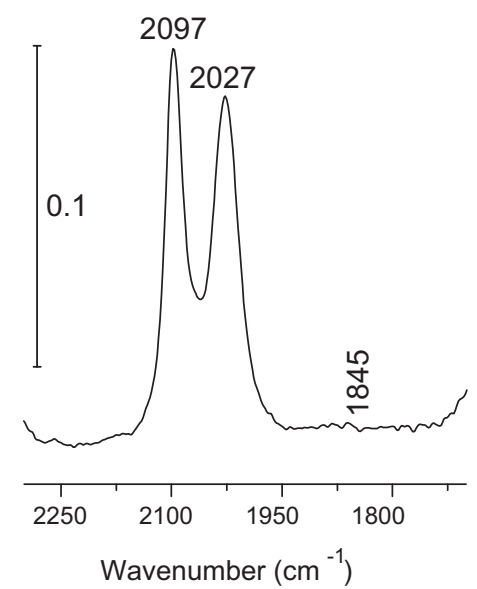

B

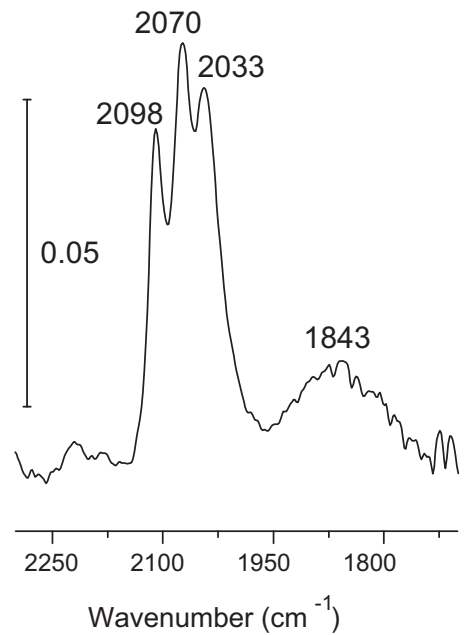

Fig. 5. FTIR spectra of adsorbed $\mathrm{CO}$ at $300 \mathrm{~K}$ : (A) $1 \% \mathrm{Rh} / \mathrm{TiO}_{2}$ nanowire and (B) $0.5 \% \mathrm{Au}+0.5 \% \mathrm{Rh} / \mathrm{TiO}_{2}$ nanowire. The $\mathrm{CO}$ pressure was $1.3 \mathrm{mbar}$.

gold covered the rhodium particles (Fig. 6B), similarly the nanowire case (Fig. 3). When $\mathrm{CO}$ was added to the bimetallic composite, the rhodium ion scattering signal showed up. These experimental data strongly support the above mentioned phenomena, namely that $\mathrm{CO}$ induces a reconstruction of the surface. Rh preferentially segregates to the surface to form $\mathrm{Rh}-\mathrm{CO}$ bond.

This process may imply the migration of Rh or Au atoms within the clusters or on the surface of the clusters. Considering that $\mathrm{Au}-\mathrm{Au}$ and $\mathrm{Au}-\mathrm{Rh}$ bonds are weaker than $\mathrm{Rh}-\mathrm{Rh}$ bonds, it may appear more probable that the movement of Au atoms is more important
A

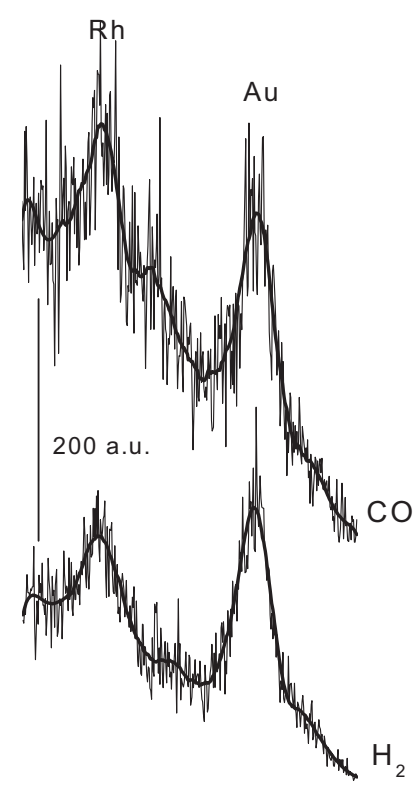

$\begin{array}{llllll}680 & 700 & 720 & 740 & 760 & 780\end{array}$

Kinetic energy [eV]
B

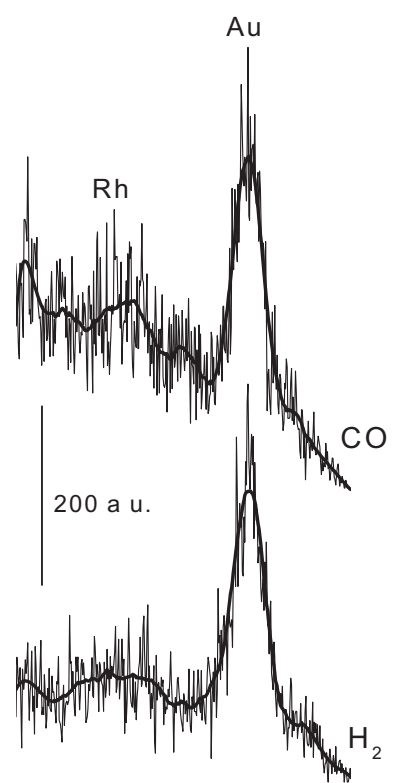

$\begin{array}{llllll}680 & 700 & 720 & 740 & 760 & 780\end{array}$

Kinetic energy $[\mathrm{eV}]$
Fig. 6. LEIS spectra of $0.25 \% \mathrm{Au}+0.75 \% \mathrm{Rh} / \mathrm{TiO}_{2}$ nanotube (A), $0.5 \% \mathrm{Au}+0.5 \% \mathrm{Rh} / \mathrm{TiO}_{2}$ nanotube (B) before and after $\mathrm{CO}$ adsorption at $300 \mathrm{~K}$. The $\mathrm{CO}$ pressure was $1.3 \mathrm{mbar}$. (the shell "opens"), while Rh atoms move less. The influence of $\mathrm{CO}$ gas in this possible process is an important question. Though the $\mathrm{Au}-\mathrm{CO}$ interaction is rather weak compared to $\mathrm{Rh}-\mathrm{CO}$ bond, in the relatively high $\mathrm{CO}$ pressure applied, the $\mathrm{CO}$ coverage on the Au capping layer is probably significant. The adsorbed CO layer presumably decreases the metal-metal bonds both for Au and Rh, leading to an increased diffusion rate. It is also possible that $\mathrm{CO}$, adsorbed in some hollow site of the Au layer can form some kind of bond with subsurface $\mathrm{Rh}$ atoms and this interaction promotes the displacement of Au atoms and the segregation of Rh.

Another possible scenario is that there is a continuous thermal fluctuation of metal atoms within the bimetallic clusters independent of the presence of $\mathrm{CO}$, and for short periods Rh atoms can be found on the cluster surface, which are subsequently trapped by $\mathrm{CO}$. The existence of this fluctuation may be possible, since significant movement of metal atoms within small clusters at room temperature was observed in several cases $[10,49,50]$ characterized by diffusion coefficients many orders of magnitude higher than the corresponding bulk values. Anyhow, further studies are needed to understand in detail the $\mathrm{CO}$ induced restructuring of $\mathrm{Rh}-\mathrm{Au}$ clusters.

\subsection{Ethanol adsorption on titanate nanowire supported catalysts}

During ethanol adsorption at room temperature predominantly the carbon-carbon bond dissociates and the carbon-oxygen bond is preserved leading to adsorbed $\mathrm{CO}$ but no to adsorbed atomic $\mathrm{O}$ on $\mathrm{Rh}(111$ ) [51] surfaces. In addition to $\mathrm{CO}$, also significant amounts of methylidyne and ethylidyne species are formed on $\mathrm{Rh}(111)$, the latter presumably via a reforming reaction. Gong and Mullins [52] reported that on $\mathrm{Au}(111)$ ethanol adsorbs only weakly and desorbs molecularly. Ethanol adsorption has been extensively studied by IR spectroscopy over $\mathrm{TiO}_{2}$ and $\mathrm{TiO}_{2}$ supported metals [53,54] among others on $\mathrm{Rh} / \mathrm{TiO}_{2}$ [55] and $\mathrm{Au} / \mathrm{TiO}_{2}$ [39], too.

Fig. 7 shows the DRIFT spectra of ethanol adsorbed on $1 \%$ $\mathrm{Au} / \mathrm{TiO}_{2}, 0.5 \% \mathrm{Au}+0.5 \% \mathrm{Rh} / \mathrm{TiO}_{2}$ and $1 \% \mathrm{Rh} / \mathrm{TiO}_{2}$ catalyst at different temperatures. Similar spectra were registered in all cases excepting the $\mathrm{CO}$ region. These results support that these species adsorbed on the nanowire. At $300 \mathrm{~K}$ absorption bands were observed at 2974, 2929 and $2875 \mathrm{~cm}^{-1}$ in the $\mathrm{C}-\mathrm{H}$ stretching region. In the low frequency range absorption bands were detected at 1448-1450 


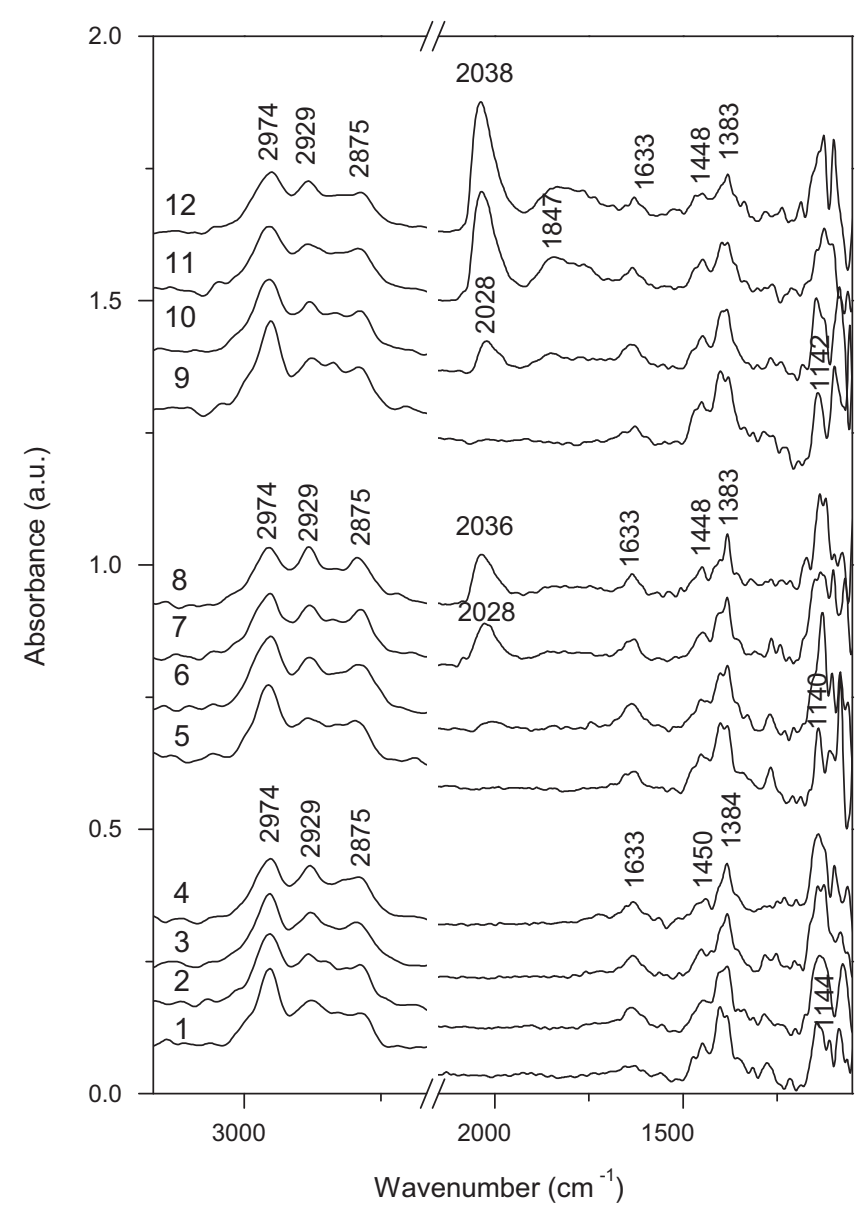

Fig. 7. Infrared spectra of ethanol adsorbed at room temperature $(1,5,9)$, at $373(2$, $6,10), 423(3,7,11), 473 \mathrm{~K}(4,8,12)$ on $1 \% \mathrm{Au} / \mathrm{TiO}_{2}$ nanowire $(1-4), 0.5 \% \mathrm{Au}+0.5 \%$ $\mathrm{Rh} / \mathrm{TiO}_{2}$ nanowire (5-8), and $1 \% \mathrm{Rh} / \mathrm{TiO}_{2}$ nanowire (9-12).

and $1383-1384 \mathrm{~cm}^{-1}$, both could be assigned as $\delta \mathrm{CH}_{3}$ vibrations of ethanol. The bands observed at 1140-1144, 1124-1121, $1069-1074,1045-1047 \mathrm{~cm}^{-1}$ could be attributed to $\nu \mathrm{C}-\mathrm{O}$ and $\mathrm{C}-\mathrm{C}$ vibrations of monodentate and bidentate ethoxide species $[39,55]$. The intensities of these bands decreased as the temperature increased but dramatic changes were not detected.

Here we focus on the $\mathrm{CO}$ region where significant differences were observed. On $\mathrm{Au} / \mathrm{TiO} 2$ we did not observe any absorbance between 2100 and $1800 \mathrm{~cm}^{-1}$ during ethanol adsorption as was found after $\mathrm{CO}$ adsorption [20]. When the $\mathrm{Rh} / \mathrm{TiO}_{2}$ was treated with ethanol above $373 \mathrm{~K}$ new peaks were detected at 2028 and $1847 \mathrm{~cm}^{-1}$. The intensities of these bands increased with increasing the temperature and the peak observed at $2028 \mathrm{~cm}^{-1}$ at room temperature shifted to higher wave numbers. The absorbance at $1847 \mathrm{~cm}^{-1}$ could be attributed to bridge bonded $\mathrm{CO}$ on Rh sites $[47,55]$. The feature of the adsorbed CO detected at $2028-2038 \mathrm{~cm}^{-1}$ is significantly differing from that depicted in Fig. 5. This discrepancy could be explained by the Rh carbonyl hydride formation (H-Rh-CO) [55,56].

When $0.5 \% \mathrm{Au}+0.5 \% \mathrm{Rh} / \mathrm{TiO}_{2}$ was the catalyst to our surprise nearly the same spectra were observed as in the case of $1 \% \mathrm{Rh} / \mathrm{TiO}_{2}$ only the intensities of the bands were weaker; at $373 \mathrm{~K}$ a small peak was detected at about $2028 \mathrm{~cm}^{-1}$ attributed to adsorbed CO.

According to the XPS results binding energies of $\mathrm{Rh}$ and Au did not alter during the ethanol adsorption even at higher temperature. The $C 1 \mathrm{~s}$ spectra showed formation of different carbon oxygen containing species $(\sim 289$ and $286.3 \mathrm{eV})$.

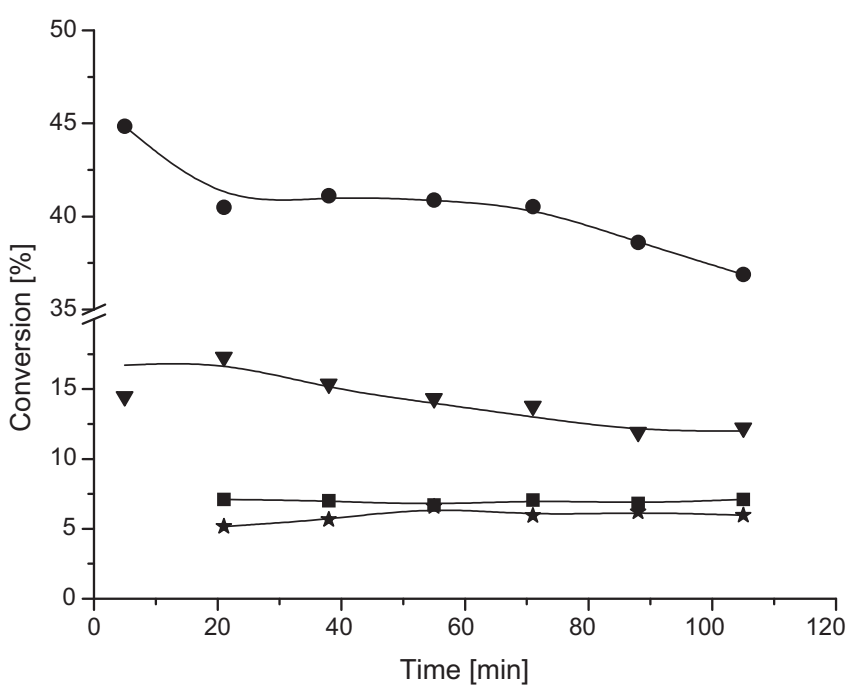

Fig. 8. The conversion of ethanol in the decomposition reaction at $603 \mathrm{~K}$ on $\mathrm{TiO}_{2}$ nanowire $(\boldsymbol{\nabla}), 1 \% \mathrm{Au} / \mathrm{TiO}_{2}$ nanowire $(\star), 0.5 \% \mathrm{Au}+0.5 \% \mathrm{Rh} / \mathrm{TiO}_{2}$ nanowire $(\boldsymbol{v})$ and $1 \%$ $\mathrm{Rh} / \mathrm{TiO}_{2}$ nanowire $(\bullet)$.

\subsection{Ethanol decomposition on titanate nanowire supported catalysts}

The ethanol decomposition was investigated at $603 \mathrm{~K}$ on $\mathrm{Au}$, $\mathrm{Rh}$ and $\mathrm{Au}-\mathrm{Rh}$ supported on titanate nanowire. The main products were in all cases carbon monoxide, methane, hydrogen, acetaldehyde, but ethylene, diethyl ether and acetic acid were also detectable. The ethanol conversion on titanate nanowire was slightly higher (7.1\%) than on $\mathrm{Au} / \mathrm{TiO}_{2}$ (6\%) (Fig. 8) but in the latter case the acetaldehyde selectivity was more than twice higher (37\%) than on the clean support. Earlier it was also found that the supported Au particles catalyze mainly the dehydrogenation of ethanol, to produce hydrogen and acetaldehyde [37]. When the catalyst contains $\mathrm{Rh}$ the conversion significantly increased; on $0.5 \%$ $\mathrm{Au}-0.5 \% \mathrm{Rh} / \mathrm{TiO}_{2}$ it was $12.2 \%$ and on $\mathrm{Rh} / \mathrm{TiO}_{2}$ the conversion was about five times higher (36.9\%) than on $\mathrm{Au} / \mathrm{TiO}_{2}$ (Fig. 8). The product distributions were similar on both samples, mainly CO was formed the acetaldehyde selectivity was only $4-6 \%$. It should be noted that in these cases the ethanol consumption decreased in time while in other cases it was stable.

From DRIFT and catalytic measurements we conclude that gold does not block entirely the adsorption and the active sites of Rh in a core-shell structure. The ethanol or the CO produced in the ethanol decomposition may also induce the segregation of Rh and the $0.5 \%$ $\mathrm{Au}+0.5 \% \mathrm{Rh}$ supported on titanate nanowire acts as an effective catalyst in ethanol decomposition.

\section{Conclusions}

1. Au and Rh clusters, as well as Au-Rh bimetallic nanoparticles were prepared on titanate nanowires, nanotubes and on $\mathrm{TiO}_{2}(110)$. The samples were characterized by X-ray photoelectron spectroscopy (XPS), low energy ion scattering spectroscopy (LEIS) and Fourier transform infrared spectroscopy (FTIR). By performing careful LEIS experiments, it was found that, for appropriate $\mathrm{Au}$ and $\mathrm{Rh}$ coverage, the $\mathrm{Au}$ almost completely covers the Rh nanoparticles. Rh core-Au shell structure was detected. The formation of this structure was not affected by alkali (K) adatoms. LEIS and FTIR showed that adsorbed $\mathrm{CO}$ at $300 \mathrm{~K}$ causes the segregation of Rh to the surface in order to bind to $\mathrm{CO}$. 
2. Rh supported on titanate nanowire exhibit a high catalytic activity in ethanol decomposition. In bimetallic form it preserves its activity because the ethanol similarly to $\mathrm{CO}$ may also induce the segregation of Rh from the Au-shell Rh-core structure.

\section{Acknowledgements}

The financial supports of the Hungarian Scientific Research Fund (OTKA) through projects K69200, K76489 and TÁMOP4.2.1/B-09/1/KONV-2010-0005 are acknowledged. We thank the preparation of titanate nanocomposites to Ákos Kukovecz and András Sápi.

\section{References}

[1] G.C. Bond, C. Louis, D.T. Thompson, Catalysis by Gold, Imperial College Press, London, 2006.

[2] M. Haruta, Gold Bull. 37 (2004) 27.

[3] G. Hutchings, J. Chem. Commun. (2008) 1148.

[4] J.A. Rodriguez, Surf. Sci. Rep. 24 (1996) 23 (and references therein).

[5] J.G. Chen, C.A. Menning, M.B. Zeller, Surf. Sci. Rep. 63 (2008) 201 (and references therein).

[6] A. Gross, Top. Catal. 37 (2006) 29.

[7] L. Guczi, Catal. Today 101 (2005) 53 (and references therein).

[8] L. Guczi, G. Boskovic, E. Kiss, Catal. Rev. Sci. Eng. 52 (2010) 133 (and references therein).

[9] L. Bugyi, A. Berkó, L. Óvári, A.M. Kiss, J. Kiss, Surf. Sci. 602 (2008) 1650.

[10] L. Óvári, L. Bugyi, Zs. Majzik, A. Berkó, J. Kiss, J. Phys. Chem. C 112 (2008) 1811.

[11] L. Óvári, A. Berkó, N. Balázs, Zs. Majzik, J. Kiss, Langmuir 26 (2010) 2167.

[12] H.L. Abbott, A. Aumer, Y. Lei, C. Asokan, R.J. Meyer, M. Sterrer, S. Shaikhutdinov, H.-J. Freund, J. Phys. Chem. 114 (2010) 17099.

[13] J.B. Park, S.F. Conner, D.A. Chen, J. Phys. Chem. C 63 (2008) 5490.

[14] S.A. Tenny, J.S. Ratliff, C.C. Roberts, W. He, S.C. Ammal, A. Heyden, D.A. Chen, J. Phys. Chem. C 114 (2010) 21652.

[15] Z. Li, F. Gao, O. Furlong, W.T. Tyose, Surf. Sci. 64 (2010) 136.

[16] K. Luo, T. Wei, C.W. Yi, S. Axnada, D.W. Goodman, J. Phys. Chem. B 109 (2005) 23517.

[17] D.R. Rainer, C. Xu, P.M. Holmblad, D.W. Goodman, J. Vac. Sci. Technol. 15 (1997) 1653.

[18] J. Kiss, R. Németh, Á. Koós, J. Raskó, J. Nanosci. Nanotechnol. 9 (2009) 3828.

[19] A. Oszkó, G. Pótari, A. Erdőhelyi, A. Kukovecz, Z. Kónya, I. Kiricsi, J. Kiss, Vacuum 85 (2011) 114.

[20] A. Kukovecz, G. Pótari, A. Oszkó, Z. Kónya, A. Erdőhelyi, J. Kiss, Surf. Sci. 605 (2011) 1048

[21] Y.N. Xia, P.D. Yang, Y.G. Sun, Y.Y. Wu, B. Mayers, B. Gates, Y.D. Yin, F. Kim, H.Q. Yao, Adv. Mater. 15 (2003) 353.
[22] F. Cesano, S. Bertarione, M.J. Uddin, G. Agostini, D. Scarano, A. Zeccina, J. Phys. Chem. C 114 (2010) 169.

[23] M. Hodos, E. Horváth, H. Haspel, A. Kukovecz, Z. Kónya, I. Kiricsi, Chem. Phys. Lett. 399 (2004) 512.

[24] G.K. Mor, K. Shankar, M. Paulose, O.K. Varghese, C.A. Grimes, Nano Lett. 5 (2005) 191.

[25] S. Kubota, K. Johkura, K. Asanuma, Y. Okouchi, N. Ogiwara, K. Sasaki, T. Kasuga, J. Mater. Sci.: Mater. Med. 15 (2004) 1031.

[26] L. Kavan, M. Kalbac, M. Zukalova, I. Exnar, V. Lorenzen, R. Nesper, M. Graetzel, Chem. Mater. 16 (2004) 477.

[27] D.V. Baviykin, A.A. Lapkin, P.K. Plucinski,J.M. Friderich, F.C. Walsh, J. Phys. Chem. B 109 (2005) 19422.

[28] R. Huang, F. Chung, E.M. Kelder, J. Electrochem. Soc. 153 (2006) 459.

[29] S.S. Malwadkar, R.S. Gholap, S.V. Awante, P.V. Korake, M.G. Chaskar, N.M. Gupta, Photochem. Photobiol. A: Chem. 203 (2009) 24.

[30] V. Idakiev, Z. Yuan, T. Tabakova, B.-L. Su, Appl. Catal. A: Gen. 281 (2005) 149.

[31] T. Akita, M. Okumura, K. Tanaka, K. Ohkuma, M. Kohyama, T. Koyanagi, M. Date, S. Tsubota S, M. Haruta, Surf. Interface Anal. 37 (2005) 265

[32] A. Erdőhelyi, J. Raskó, T. Kecskés, M. Tóth, M. Dömök, K. Baán, Catal. Today 116 (2006) 367.

[33] J. Raskó, M. Dömök, K. Baán, A. Erdőhelyi, Appl. Catal. A: Gen. 299 (2006) 202.

[34] M. Scott, M. Goeffroy, W. Chiu, M.A. Blackford, Top. Catal. 51 (2008) 13.

[35] M. Dömök, A. Oszkó, K. Baán, I. Sarusi, A. Erdőhelyi, Appl. Catal. A: Gen. 383 (2010) 33.

[36] R.M. Navarro, M.A. Peña, J.L.G. Fierro, Chem. Rev. 107 (2007) 3952.

[37] A. Gazsi, A. Koós, T. Bánsági, F. Solymosi, Catal. Today 160 (2011) 70

[38] P.-Y. Sheng, G.A. Bowmaker, H. Idriss, Appl. Catal. A: Gen. 261 (2004) 171.

[39] M.A. Nadeem, M. Murdoch, G.I.N. Waterhouse, J.B. Metson, M.A. Keane, J. Llorca, H. Idriss, J. Photochem. Photobiol. A: Chem. 216 (2010) 250.

[40] Y. Guan, E.J.M. Hensen, Appl. Catal. A: Gen. 361 (2009) 49.

[41] M.J. Lippits, B.E. Nieuwenhuys, J. Catal. 274 (2010) 142.

[42] E. Horváth, Á. Kukovecz, Z. Kónya, I. Kiricsi, Chem. Mater. 19 (2007) 927.

[43] Á. Kukovecz, M. Hodos, E. Horváth, Gy. Radnóczi, Z. Kónya, I. Kiricsi, J. Phys Chem. B 109 (2005) 17781.

[44] L.Z. Mezey, J. Giber, Jpn. J. Appl. Phys. 21 (1982) 1569.

[45] J. Kiss, K. Révész, F. Solymosi, Surf. Sci. 207 (1988) 36.

[46] L.K. Ono, B.R. Cuenya, J. Phys. Chem. C 112 (2008) 4676.

[47] F. Solymosi, M. Pásztor, J. Phys. Chem. 89 (1985) 4789.

[48] F. Gao, Y. Wang, D.W. Goodman, J. Phys. Chem. C 114 (2010) 4036.

[49] O. Ozturk, J.B. Park, S. Ma, J.S. Ratliff, J. Zhou, D.R. Mullins, D.A. Chen, Surf. Sci. 601 (2007) 3099.

[50] R. Ferrando, J. Jellinek, R.L. Johnston, Chem. Rev. 108 (2008) 845.

[51] A. Resta, J. Gustafson, R. Westerström, A. Mikkelsen, E. Lundgren, J.N. Andersen, M.M. Yang, X.F. Mab XF, X.H. Bao, W.X. Li, Surf. Sci. 602 (2008) 3057.

[52] J. Gong, B. Mullins, J. Am. Chem. Soc. 130 (2008) 16458.

[53] G.A.M. Hussein, N. Sheppard, M.I. Zaki, R.B. Fahim, J. Chem. Soc. Faraday Trans. 87 (1991) 2661.

[54] L. Óvári, F. Solymosi, Langmuir 18 (2002) 8829.

[55] J. Raskó, A. Hancz, A. Erdőhelyi, Appl. Catal. A: Gen. 269 (2004) 13.

[56] F. Solymosi, A. Erdőhelyi, M. Kocsis, J. Catal. 65 (1980) 428. 